\title{
Reinforcement of magnesium Elektron 21 with aluminium nitride (AIN) nanoparticles dispersed using a travelling magnetic field
}

\author{
Mariano Garrido ${ }^{1}$, Laurent Davoust ${ }^{1, *}$, Rémi Daudin ${ }^{1}$, Luc Salvo ${ }^{1}$, Wim Sillekens ${ }^{2}$, and Yves Fautrelle $^{1}$ \\ ${ }^{1}$ Univ. Grenoble-Alpes / Grenoble-INP / CNRS, SIMaP, 38402 Saint Martin d'Hères, France \\ ${ }^{2}$ European Space Agency, PO Box 299, 2200 AG Noordwijk, The Netherlands
}

Received: 28 October 2019 / Accepted: 2 March 2020

\begin{abstract}
Magnesium alloy Elektron 21 is commonly used in aerospace structural parts in which good creep resistance and lightness are required. This alloy maintains good mechanical properties at temperatures as high as $200^{\circ} \mathrm{C}$. One mechanism with high potential for improving mechanical properties of magnesium alloys at a high temperature is dispersion-strengthening based on nanoparticles. In this paper, we analyse the properties of magnesium Elektron 21 samples solidified with nanoparticles of aluminium nitride dispersed by an electromagnetic stirring provided from a travelling magnetic field. X-ray tomography and X-ray spectrometry as well as compression tests at several temperatures $\left(350,400\right.$ and $\left.450^{\circ} \mathrm{C}\right)$ are carried out on samples containing the nanoparticles. The present study extends the knowledge on the processing by alternative techniques and on the enhancement of creep behaviour at higher temperatures for such metal matrix composites compared to previous studies.
\end{abstract}

Keywords: metal matrix composites / electromagnetic stirring / creep resistance / hot deformation behaviour / constitutive equation / deformation activation energy

\section{Introduction}

The use of magnesium ELEKTRON $21(\mathrm{Mg}$ EK21) in industry is widespread. Because of its light weight, its high strength as well as its fully heat treatable properties, that magnesium based alloy is designed to be used for structural applications subjected to high temperature, such as aerospace applications and high performance automotive applications such as transmission casing. Magnesium EK21 is a multiple component alloy. It mainly contains zinc, zirconium and rare earths such as neodymium and gadolinium which provide high strength at high temperatures and also a great potential for precipitation strengthening. Zirconium serves as grain refiner. It improves its mechanical properties at ambient temperature and enhances its corrosion resistance. Dispersion-strengthening using ceramic nanoparticles which are theoretically stable at high temperatures holds a high potential as a method to improve high temperature properties of magnesium alloys. The reinforcement of metal matrices using ceramic can be achieved by different mechanisms, such as Orowan pinning of dislocations or by restricting grain boundary sliding $[1,2]$. Ferkel and Mordike [3] analyzed dispersion of $\mathrm{SiC}$ nanoparticles in pure magnesium prepared with a powder metallurgical

\footnotetext{
* e-mail: Laurent.davoust@simap.grenoble-inp.fr
}

(PM) method. They put forth the improvement of its creep resistance. This feature was related to Orowan strengthening and dislocation generation. According to Liu et al. [4], dispersion of nanoparticles of aluminium nitride (AlN) into nanocrystalline aluminium enhanced its hardness and elastic modulus. Reinforcement of magnesium alloy AZ91 using also AlN particles was also achieved by Paramsothy et al. [5]. One of the peculiarities presented by AlN particles is its lattice parameter which is similar to the one presented by pure magnesium. This feature makes this particle a potential grain refiner for magnesium matrices [6].

According to different authors improvement of mechanical properties of particulate reinforced composites highly depends on the good dispersion of the particles within the matrix material [7]. For example, Zhang [8] demonstrated that a good spatial distribution of $\mathrm{SiC}$ particles in aluminium samples produces much higher improvements in tensile strength and hardening rate. Therefore, the maximum reinforcement potential of the particles is highly dependent on the method used to disperse them. Here, the aim of this paper is to analyze the microstructural and mechanical analysis of magnesium EK21-based samples in which particles of AlN are electromagnetically dispersed using a travelling magnetic field. Furthermore, because of the moderate density of AlN particles (approximately equal to $3.3 \mathrm{~g} / \mathrm{cm}^{3}$ ) sedimentation velocity (approximately equal respectively to $0.64 \times 10^{-9} \mathrm{~m} / \mathrm{s}$ for $30 \mathrm{~nm}$-diameter spherical 
particles and $2.6 \times 10^{-5} \mathrm{~m} / \mathrm{s}$ for $5.8 \mu \mathrm{m}$ diameter spherical AlN clusters in a magnesium melt according to Stokes viscous drag) remains negligibly small compared to the stirring velocity (equal to $0.4 \mathrm{~m} / \mathrm{s}$ ). Electromagnetic stirring offers several advantages. Firstly, it is a contact-less actuator which avoids any melt contamination. Secondly, the flow pattern as well as its amplitude can be controlled in a quite accurate way until the end of solidification.

Section II is devoted to the description of the set-ups used in the experiments and the experimental protocol associated. Sample characterization methodology and details of the mechanical tests are provided. The results are presented in Section III and discussed in Section IV. Some conclusions are provided in Section V.

\section{Apparatus, materials and methodology}

The experiments comprise two successive steps. The first one is to develop the master EK21 alloy (magnesium Elektron 21, composition $0.2-0.5 \mathrm{wt} . \%$ zinc, $2.6-3.1 \mathrm{wt} . \%$ neodymium, 1.0-1.7 wt.\% gadolinium, 0.4 wt.\% zirconium, magnesium balanced) by introducing the AlN nanoparticles into magnesium EK21 alloy. The size of AlN particles ranges between 30 to $40 \mathrm{~nm}$, whereas the amount of $\mathrm{AlN}$ is $1 \mathrm{wt} . \%$. Aluminium nitride spherical nanoparticles were provided by Tomsk State University (Russia). Characterization of the particle distribution put forth the existence of AlN clusters, the average size of which is approximately $5.8 \mu \mathrm{m}$. Characterization of the particle clusters is detailed in Annex 1. The device is illustrated in Figures 1a-1c. The procedure consists of melting the EK21 alloy in an induction furnace and then injecting a capsule containing the particles. The capsule, made of the same metal, is prepared separately in a glove box. The important electromagnetic stirring allows fusion of the capsule delivery and a first dispersion of the particles in the bath. After solidification, the samples so produced contain $1 \%$ in weight of aluminium nitride nanoparticles of 30 to $40 \mathrm{~nm}$ average size.

The second stage consists of solidifying samples in a vertical Bridgman furnace (VB2) under a well-controlled strong electromagnetic stirring (see Fig. 1d). The electromagnetic stirring system used in the current study is produced by a Bitter coil electromagnet configured to produce a travelling magnetic field (TMF) as large as $15 \mathrm{mT}$ and frequency of $50 \mathrm{~Hz}[9]$. The pole pitch is equal to $0.09 \mathrm{~m}$. The typical liquid velocities are of the order of $0.4 \mathrm{~m} / \mathrm{s}$ for $B=15 \mathrm{mT}$. The flow regime is turbulent, and the velocities are proportional to the magnetic field amplitude. Such an efficient stirring allows additional dispersion of the particles together with heat and mass transfer enhancement. The remelting of the magnesium samples is performed using a graphite resistance furnace. This furnace described in Figure 1d, is provided with two distant zones separated by a temperature gradient controlled area in which the crucible is placed. The heating is performed using graphite resistors placed on the upper and lower parts of the furnace. The material is directionally solidified by controlling the temperature of the resistors. The furnace is subjected to vacuum conditions of $10^{-3} \mathrm{mbar}$ at the beginning of the experiments. Afterwards, an open cycle of argon $2.3 \mathrm{l} / \mathrm{min}$ is maintained during the duration of the experiment. The

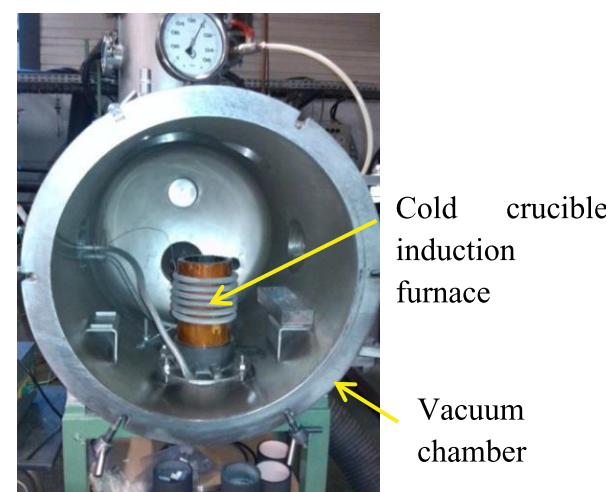

(a)

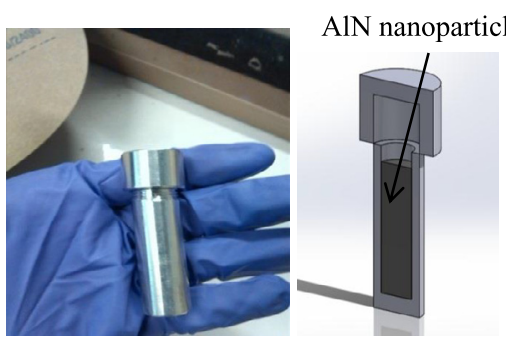

(b)

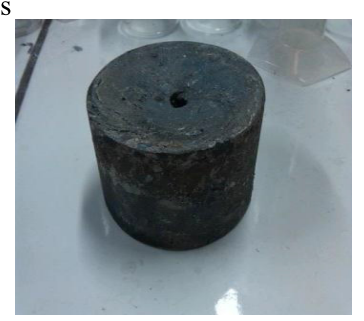

(c)

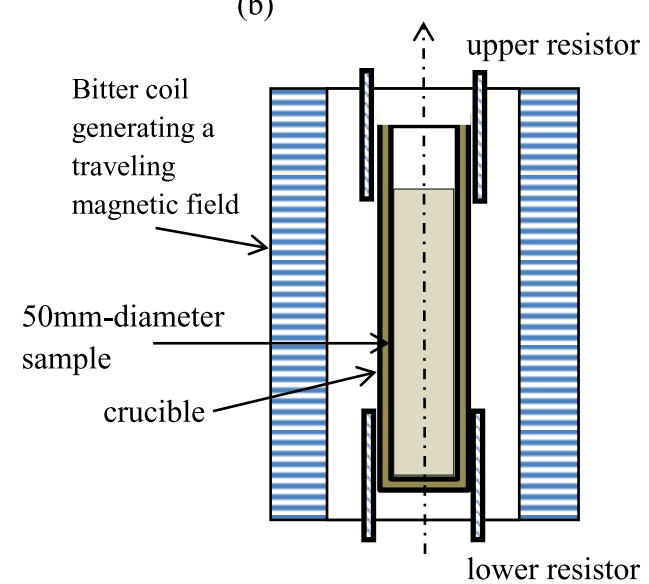

(d)

Fig. 1. Apparatus used in the experiments. a: Induction furnace devoted to elaboration of the master alloys. View of the cold crucible located in a vacuum chamber. The supply frequency is $14 \mathrm{kHz}$ and the total Joule power ranges between 8 to $14 \mathrm{~kW}$; b: View and scheme of the capsule containing AlN nanoparticles to be immersed in the liquid metal matrix. The capsule was prepared in a glove box; c: View of the final master alloy ingot; d: Scheme of the Bridgman furnace used to solidify the sample under controlled electromagnetic stirring (VB2) produced by a traveling magnetic field.

capsules are melted with pieces of magnesium EK21 at a maximum temperature of $800^{\circ} \mathrm{C}$. Electromagnetic stirring is applied after the temperature reaches $640^{\circ} \mathrm{C}$ and it is maintained until the end of the solidification. The directional solidification parameters are:

\footnotetext{
- cooling rate: $0.2 \mathrm{~K} / \mathrm{s}$;

- temperature gradient: $666 \mathrm{~K} / \mathrm{m}$.
} 
Table 1. Values of applied strain rate for the corresponding strain range.

\begin{tabular}{lllllllll}
\hline$\varepsilon$ & $0-0.1$ & $0.1-0.15$ & $0.15-0.2$ & $0.2-0.25$ & $0.25-0.3$ & $0.3-0.35$ & $0.35-0.4$ & $0.4-0.45$ \\
$\frac{d \varepsilon}{d t}\left(10^{-3} \mathrm{~s}^{-1}\right)$ & 1 & 0.2 & 0.4 & 1 & 0.8 & 2 & 4 & 8 \\
\hline
\end{tabular}

\subsection{Mechanical analysis using high temperature compression tests with strain-rate jumps}

In order to measure the consequences of electromagnetic stirring on the mechanical properties of magnesium EK21 produced by the dispersion of the AlN particles, samples of pure material populated (or not) by AlN particles are tested using hot compression tests. Information such as material creep resistance, flow behaviour as well as activation energies, that are useful for practical applications, can be obtained using such mechanical tests. The compression tests are performed using an Instron Industrial Series 300DX system jointly with a Model SF-16 split furnace. The samples processed in the Bridgman furnace, are cylindrical (3 $\mathrm{mm}$ in diameter and $4.5 \mathrm{~mm}$ in length) for the purpose of characterization. For the tests performed at $350{ }^{\circ} \mathrm{C}$ (respectively 400 and $450^{\circ} \mathrm{C}$ ), each sample is heated from room temperature up to $310^{\circ} \mathrm{C}$ (respectively 375 and $433^{\circ} \mathrm{C}$ ) with a heating rate of $19^{\circ} \mathrm{C} \mathrm{min}^{-1}$. Then, the heating rate is decreased to $10^{\circ} \mathrm{Cmin}^{-1}$ until the temperature increases up to $356^{\circ} \mathrm{C}$ (respectively 406 and $453^{\circ} \mathrm{C}$ ). Afterwards, the temperature is decreased at a cooling rate of $1.5^{\circ} \mathrm{C} \mathrm{min}^{-1}$ until reaching $350^{\circ} \mathrm{C}$ (respectively 400 and $450^{\circ} \mathrm{C}$ ). It is left to stabilize at the target temperature during 10 minutes, then compression tests with strain rates jump are performed. The imposed strain rates as a function of the strain values are listed in Table 1.

\subsection{Microstructural characterisation of samples}

The nanoparticle dispersion and the microstructure of EK21 (with or without AlN particles) are analysed using $\mathrm{X}$-ray tomography. This technique is based on the use of $\mathrm{X}$-ray measurements taken with different orientations of the sample which produce, after reconstruction, crosssectional (tomographic) images. These images are used to produce 3D compositions in which the internal structure of the sample is revealed. The tests were performed using the $\mathrm{X}$-ray beam provided by the European synchrotron radiation facility (ESRF) at Grenoble (France). The tomographic analysis is produced using an X-ray beam of $19 \mathrm{keV}$ and a scan time of $5 \mathrm{~s}$. With such configuration, images of $645 \mathrm{~nm} /$ pixel resolution of $0.10 \mathrm{~mm}^{3}$ magnesium samples are obtained. Nano particles were not found using tomography, only particle agglomerates are detected by means of this technique. It was possible to characterize the average distance and size of AlN clusters. An illustration of the methodology is provided in Figure 11 of Annex 1. Such a resolution allowed also us to detect some intermetallic particles like AlZr compounds (cf. Figs. 3 and 5). Such 3D images are used to calculate the average cluster size and the average cluster-cluster distance making use of ImageJ and Matlab. Some details of methodology are provided in Annex 1. The analysis of the chemical composition of

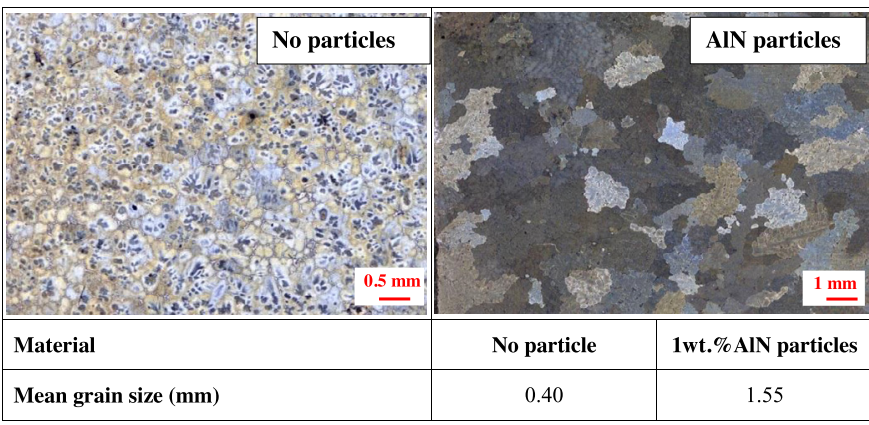

Fig. 2. Optical micrographs of EK21 (left) and EK21+AlN (right) samples. Below are indicated the grain sizes.

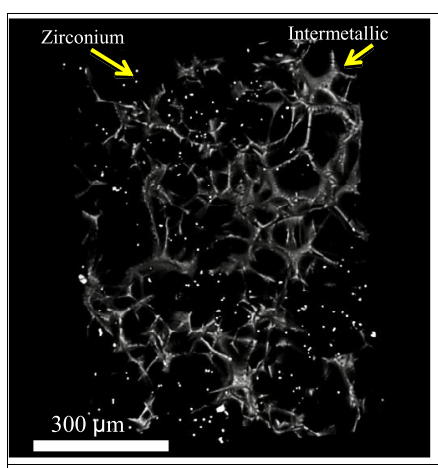

Pure Mg EK21

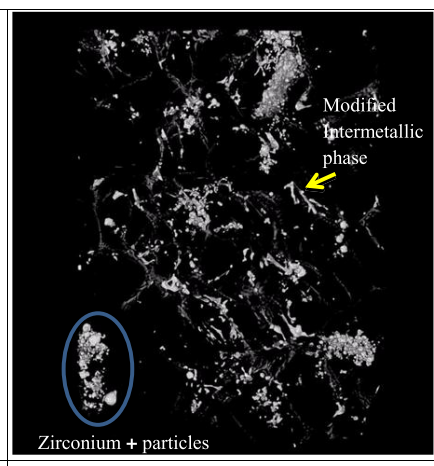

Mg Ek21 + 1wt.\% AlN nanoparticles
Fig. 3. Tomographic view of the grain boundaries. Thresholded 3D images of EK21 (left) and $(\mathrm{EK} 21+\mathrm{AlN})$, side view.

samples containing AlN nanoparticles is carried out using Energy-Dispersive X-ray spectrometry (EDS) and X-ray diffraction.

\section{Results}

\subsection{Structural and chemical analysis}

Two samples of magnesium Elektron 21 produced using an electromagnetic stirring of $70 \mathrm{mT}$ are presented in Figure 2. The sample on the left is the pure material whereas the sample on the right contains $1 \%$ in weight of AlN nanoparticles. Both materials present an equiaxial grain structure, but the material containing nanoparticles presents a bigger grain size with respect to the pure alloy material, from $0.4 \mathrm{~mm}$ in average for "pure" EK21 to $1.55 \mathrm{~mm}$ for EK21 + 1wt.\%AlN. Such a trend could be a consequence of stirring which destroy nucleant elements in the bath. In addition, the turbulent electromagnetic stirring could have accelerated the reaction between zirconium and AlN enhancing the 


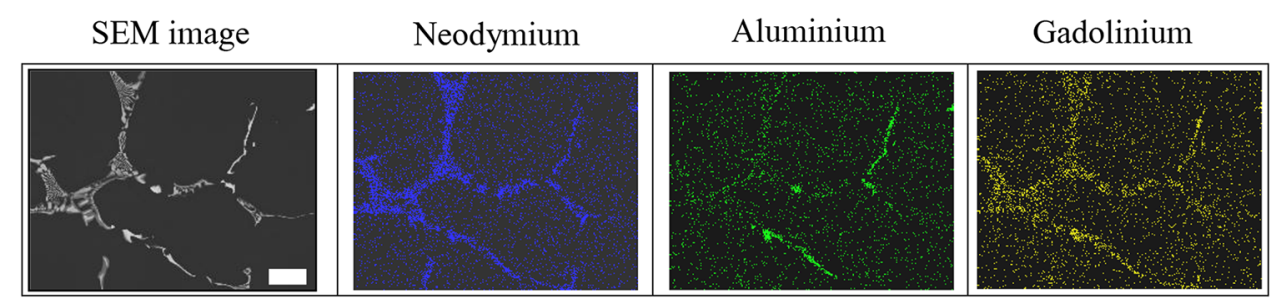

Fig. 4. EDS analyses of the intermetallic phase. The width of each image is $240 \mu \mathrm{m}$.

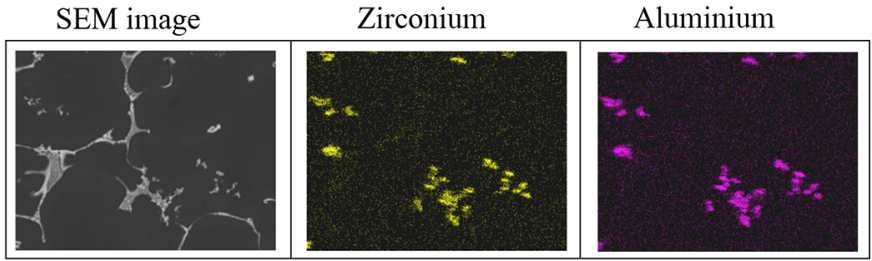

Fig. 5. EDS analyses of identified particles showing presence of AlZr phases within the $\mathrm{Mg}$ matrix. The width of each image is $240 \mu \mathrm{m}$.

formation of intermetallics such as Al4Zr5 or ceramic particles such as $\mathrm{ZrN}$. Some clues of the latter effects are indicated in Annex 2.

The internal structure of both materials presented is also studied producing X-ray tomographic volumes. Two of the samples are displayed in Figure 3 . The image on the left presents the pure material in which two types of structures are visualised: the first one, in dark grey colour, is the intermetallic phase which contains gadolinium and neodymium; while the second one rich in zirconium is made visible according to bright spots well dispersed within the intermetallic phase (Fig. 5). The image on the right presents a sample of magnesium EK21 containing AlN nanoparticles. In this case, the intermetallic phase present morphological changes with respect to the phase presented in the pure material and zirconium rich areas can be seen containing particle type structures or agglomerates. Dark areas within the grey structures in both materials contain the magnesium $a$-phase.

The analysis of several samples of Mg EK21 + 1wt.\% AlN demonstrates the presence of particle agglomerates with an average volume of $178 \mu \mathrm{m}^{3}$ or a Sauter diameter of $5.83 \mu \mathrm{m}$. The chemical analysis of the material containing nanoparticles is performed using X-ray spectrometry EDS. It demonstrates the presence of aluminium in the intermetallic areas containing gadolinium and neodymium (Fig. 4) and particles are made evident within the magnesium matrix containing zirconium and aluminium (Fig. 5).

The presence of aluminium in the intermetallic phase could be related to the rejection of the particles by the solidification front during the cooling of the master sample. Some of the particles present in the intermetallic phase could have reacted with the different elements present in it, forming compounds. The detection of aluminium next to zirconium as shown in Figure 5 supports the fact that particles chemically react with the elements present in the alloy. In order to determine the reactivity of the particles with the elements of the alloy in play at the conditions of the experiments, the equilibrium reactions between AlN and magnesium were calculated using the thermochemical software FactSage. Considering the following experimental conditions: $1 \%$ in weight of AlN particles in magnesium alloy EK21, under argon atmosphere (pressure: 1 bar, maximum temperature: $800^{\circ} \mathrm{C}$ ). The results, displayed in Table 2, indicate that $36 \%$ of the particles are dissolved in contact with the magnesium matrix releasing $23 \%$ of their weight as pure aluminium. The results indicate a high tendency of aluminium to react with neodymium and gadolinium producing potential compounds such as AlGd or $\mathrm{NdAl}_{2}$. The formation of Al-RE compounds was confirmed by the analysis produced using X-ray diffraction on a sample of magnesium EK21 + 1wt.\% AlN. The results of the test confirmed the presence of $\mathrm{NdAl}_{2}$ as shown in Figure 6.

\subsection{Mechanical analysis}

The compression curves with strain rate jumps obtained with pure magnesium EK21 and magnesium EK21 + 1wt. $\%$ AlN at $350{ }^{\circ} \mathrm{C}$ are depicted in Figure 7 . The changes of the applied strain rate during the compression test produce a step-like curve from which the behaviour of the specimen can be extrapolated using the different stress plateaux.

A rapid increase in the flow stress at the beginning of the test is made evident, which is rather pronounced in the material containing nanoparticles. The test shows that flow stresses in the material reinforced with AlN nanoparticles increases by $20 \%$ at large strain rates, whereas low strain rates present enhancements of approximately 20 to $50 \%$ with respect to the unreinforced material. The stress-strain curves displayed for the reinforced alloy magnesium EK21 + 1wt.\% AlN exhibit a serrated flow behaviour in the end of the test. This typical behaviour could be related to the motion of dislocations which interact with precipitates impeding their motion. The motion of the dislocations affected by a stop and go behaviour due to their pinning with precipitates corresponds to the stress fluctuation depicted as a serration in the stress-strain curve [10]. The stress-strain curve resulting from the initial loading into the plastic range can be approximated using the following power law equation, initially proposed by Norton to describe creep under low stresses [11] which includes a threshold stress parameter $\sigma_{t}$ when it is applied to nanocomposites, which leads to a 
Table 2. Results of the thermochemical analysis showing potential reaction between $\mathrm{Al}$ and EK21 with subsequent production of side-compounds.

\begin{tabular}{lllllll}
\hline Constituents & $\mathrm{Mg}_{2} \mathrm{Nd}_{-} \mathrm{Mg}_{2} \mathrm{Re} \_\mathrm{Mg}_{2} \mathrm{Nd}(\mathrm{s})$ & $\mathrm{AlGd}(\mathrm{s})$ & $\mathrm{ZrN}(\mathrm{s})$ & $\mathrm{AlN}$ & $\mathrm{NdAl}_{2}(\mathrm{~s})$ & $\mathrm{Nd}_{-} \mathrm{Solid}-\mathrm{A}(\mathrm{s})$ \\
Equlibrium gram & 3.17 & 1.4 & 0.922 & 0.64 & 0.359 & 0.092 \\
\hline
\end{tabular}

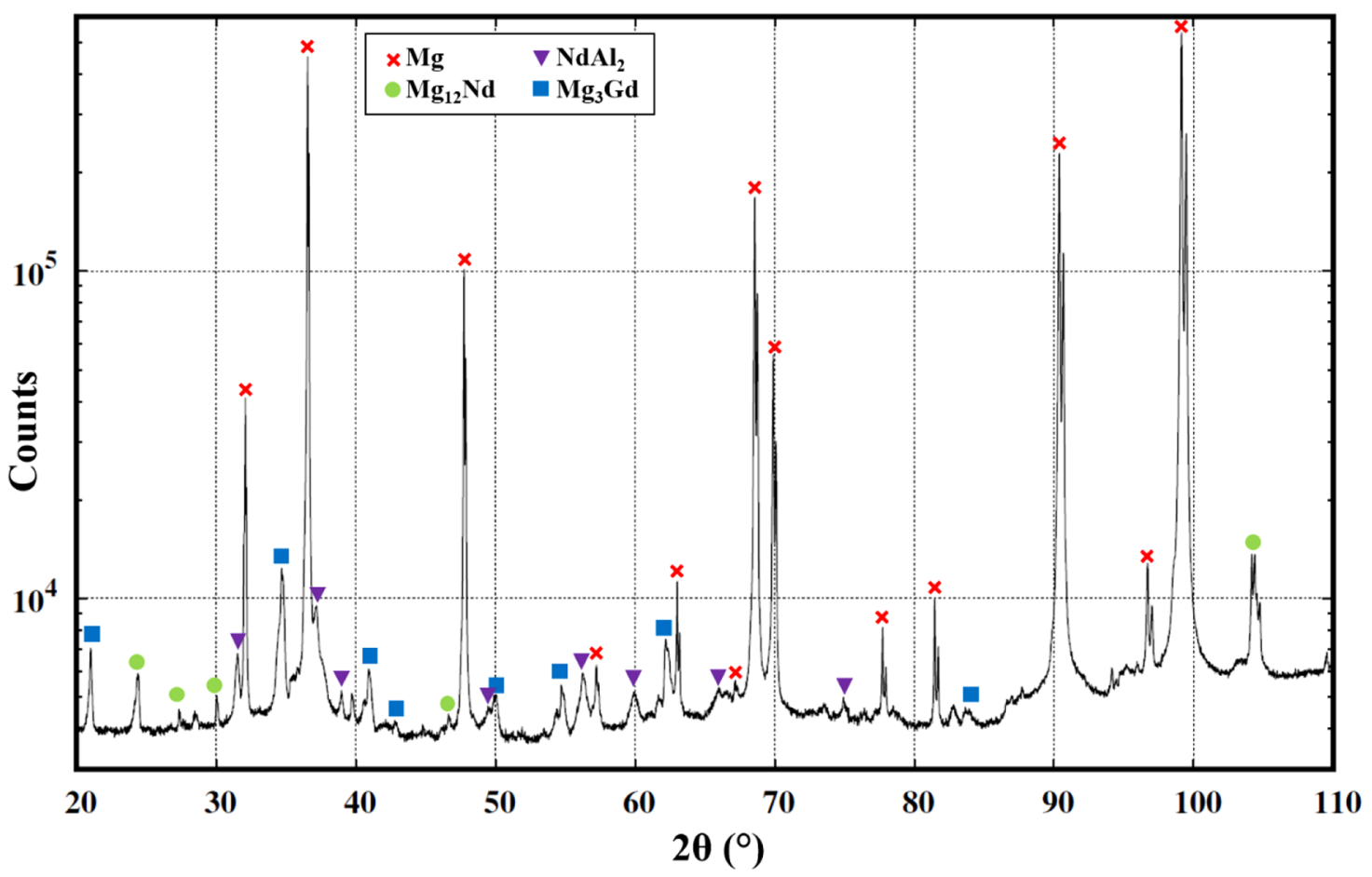

Fig. 6. X-ray diffractogram of EK $21+1$ wt.\% AlN.

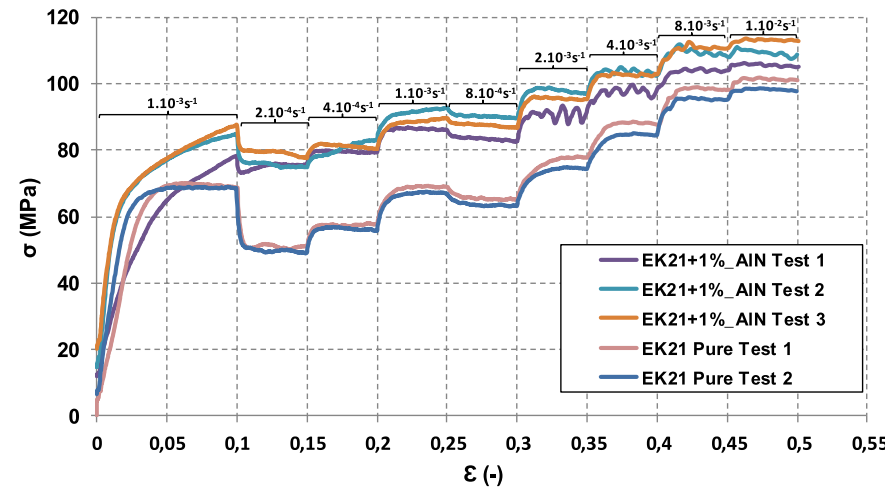

Fig. 7. Strain-stress curves obtained during the compression tests with strain rate jumps at $350^{\circ} \mathrm{C}$ for EK21 (2 tests) and EK21 + AlN particles (3 tests).

corrected constitutive law:

$$
\dot{\varepsilon}=k\left(\sigma-\sigma_{t}\right)^{n},
$$

where $\dot{\varepsilon}$ is the steady creep rate, $\sigma$ is the flow stress required for plastic deformation at the given temperature, $k$ is a constant which depends on the material characteristics
(Young's modulus, diffusion coefficient, grain size, activation energy, Burger vector) and $n$ is the strain hardening exponent which is linked to deformation mechanisms such as dislocation climb, diffusion or grain boundary sliding. The parameter $\sigma t$ can therefore be considered as a threshold stress below which creep is no longer detected. Using a fit based on a least squares method and equation (2), the exponent $n$ is found very close to the value, $n=5$. According to the literature, an $n$ value ranging from 3 to 7 indicates that climb-controlled dislocation creep is the dominant deformation process $[12,13]$. The log-log plots of strain rates as a function of stress values extracted from the mean values of the plateau on the strain-stress curves are depicted in Figure 8 and a summary of the results is presented in Table 3.

The threshold stress and the $k$ coefficient as identified from the previous identification process are presented in Table 3. The results show a significant enhancement in creep resistance of the material reinforced with AlN nanoparticles. This effect was also observed (cf. Katsarou et al. [14] and Yang et al. [15]) and the values of the threshold stresses are of the same order of magnitude.

Hot compression tests with strain rate jumps were performed with the objective of measuring flow stresses at temperatures of 350,400 and $450{ }^{\circ} \mathrm{C}$. 


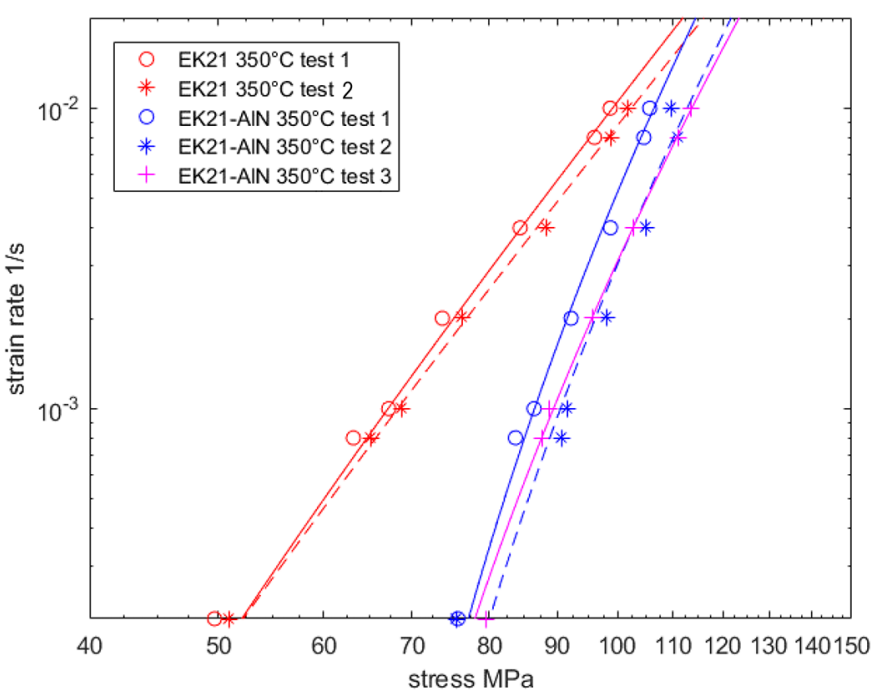

Fig. 8. Log-log plots of strain rates as a function of stress values extracted from the mean values of the plateau on the stain-stress curves. Dots are experimental data while lines show the best fit obtained the power law and a threshold stress. Values are given in Table 3.

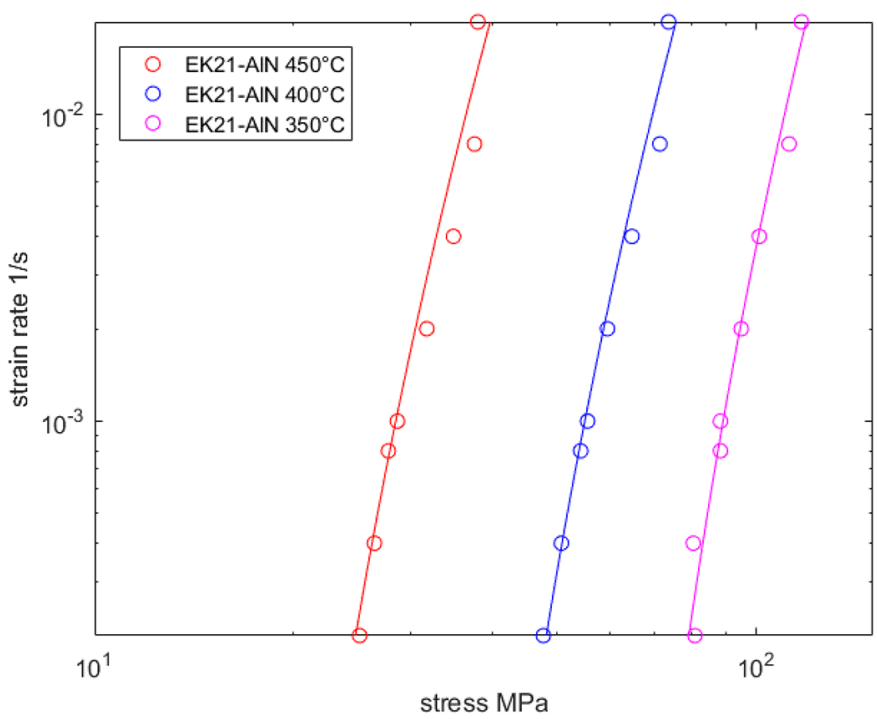

Fig. 9. Log-log plots of the strain rate versus stress taken from the compression test curves of the $\mathrm{Mg}$ EK $21+1 \mathrm{wt} . \%$ AlN sample at $350{ }^{\circ} \mathrm{C}$ (magenta), $400^{\circ} \mathrm{C}$ (blue) and $450{ }^{\circ} \mathrm{C}$ (red).

Figure 9 presents experimental data and the fit obtained with a fixed value of $n=5$. Values for the preexponential term and threshold stress are given in Table 3. As expected, the threshold stress is decreasing with the temperature. Using the following relation describing the steady-state creep rate dependence to stress and temperature $(T$ in $\mathrm{K})$ :

$$
\dot{\varepsilon}=\left(\sigma-\sigma_{t}\right)^{n} e^{-\left(\frac{Q}{R T}\right)},
$$

with $R$ the universal constant of gases and $Q$ the activation energy $(\mathrm{J} / \mathrm{mol})$ and plotting the $\log (\sigma-\sigma t)$ versus $1 / n R T$ for the various strain rates used during the strain rate jump
Table 3. Values of $k$ and $\sigma t$ extracting form the fit of the experimental data using equation (1) and $n=5$.

\begin{tabular}{llll}
\hline $\begin{array}{l}\text { Temperature } \\
\left({ }^{\circ} \mathrm{C}\right)\end{array}$ & Material/test & $k$ & $\begin{array}{l}\sigma t \\
\text { MPa }\end{array}$ \\
\hline 350 & Mg EK21 test 1 & $2.05 \mathrm{e}-12$ & 12.5 \\
350 & Mg EK21 test 2 & $1.49 \mathrm{e}-12$ & 10 \\
350 & Mg EK21 1\% AlN test 1 & $2.19 \mathrm{e}-11$ & 52.5 \\
350 & Mg EK21 1\% AlN test 2 & $1.28 \mathrm{e}-11$ & 52.5 \\
350 & Mg EK21 1\% AlN test 3 & $8.19 \mathrm{e}-12$ & 48 \\
400 & Mg EK21 1\% AlN & $1.1 \mathrm{e}-10$ & 30 \\
450 & Mg EK21 1\% AlN & $2.1 \mathrm{e}-9$ & 15 \\
\hline
\end{tabular}

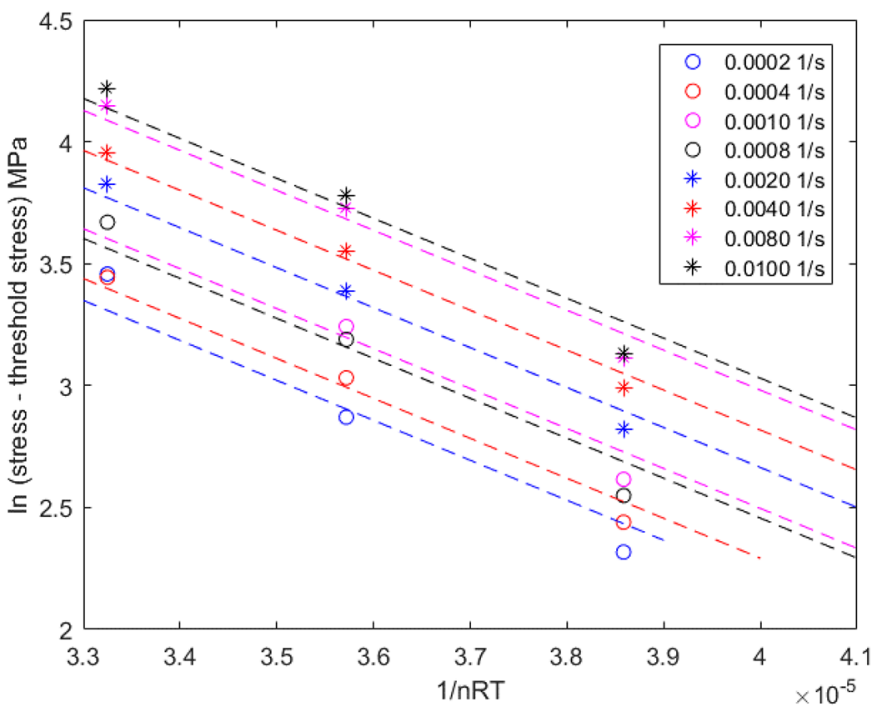

Fig. 10. $\log (\sigma-\sigma t)$ vs $1 / n R T$ extracted from the compression test curves of the $\mathrm{Mg} \mathrm{EK} 21+1 \%$ AlN.

tests (Fig. 10), we can compute the activation energy for each strain rate. A value of $Q=167 \pm 6 \mathrm{~kJ} / \mathrm{mol}$ is obtained which is slightly higher than the one for the magnesium self-diffusion energy (136 kJ/mol) [16,17] but close to it and with threshold stresses similar to the one obtain by Klosch et al. [18]. This could be explained by the presence of rare earth elements.

\section{Discussion}

The addition of AlN nanoparticles to magnesium EK21 produces measurable changes in the microstructure and mechanical properties of the material. The first effect observed is an increase in grain size with respect to the pure material processed under the same casting conditions. The reinforced material presents an average grain size $200 \%$ larger than the average grain size of pure magnesium EK21. The study of the equilibrium reactions of AlN with pure magnesium shows that an amount equivalent to $0.3 \%$ in weight of aluminium is released into the magnesium matrix under the casting conditions 
applied during the experiments. The aluminium dissolves in the melted magnesium and tends to react with the available elements in the alloy such as zirconium which is used as grain refiner. It is likely that the significant electromagnetic stirring accelerates the dissolution kinetics. The reactions involving zirconium and aluminium produces different compounds such as $\mathrm{AlZr}$ or $\mathrm{NdAl}_{2}$. The lattice mismatch between zirconium and magnesium is reported to be less than 1\% [19], whereas the lattice mismatch between AlZr and magnesium is approximately $4 \%$, suggesting that this type of particle is not welladapted as a grain refiner of magnesium matrices. The formation of these particles is suspected to reduce the grain refinement effect of zirconium and consequently to be responsible for the increase of the grain size observed. In the same system EK21 + AlN particles Yang et al. [15] found that the grain size was slightly reduced but ultrasound waves were used to disperse particles with further enhancement of grain refinement. Aluminium was also found in the intermetallic phase rich in Gadolinium and Neodymium. The high difference of electro negativity between aluminium and RE elements leads to a high tendency to form Al-RE compounds [19,20]. Aluminium compounds containing rare earths or zirconium such as $\mathrm{Al}_{3} \mathrm{Zr}$ have been related to the enhancement of creep strength on different alloys such as $\mathrm{Mg}-\mathrm{Li}-\mathrm{Al}$ [21]. The effect of this type of compound in the mechanical performance of the alloy should be assessed, but different studies such as the one performed by Meshinchi Asl [22], have shown that particles of $\mathrm{Al}_{11} \mathrm{RE}_{3}$ improve the creep resistance of magnesium AZ91. The formation of $\mathrm{AlNd}_{2}$ compounds was predicted by thermodynamic calculations and confirmed during XRD analysis of the materials produced. These particles were also detected in studies performed by Saboori et al. [23] in which dispersion of EK21 and AlN nanoparticles was produced by an ultrasound-assisted casting. The presence of aluminium in the intermetallic phase can be also related to the presence of AlN nanoparticles rejected to grain boundaries during solidification. The presence of AlN nanoparticles in grain boundaries has been detected in a similar study by Mounib et al. [24], showing that despite the partial dissolution of the particles during material processing, most of the nanoparticles survived. The presence of particles in the intergranular space could have contributed to the reinforcement of the material related to intergranular reinforcement.

\section{Conclusion}

The effects on the microstructure and the creep resistance issued from the incorporation of AlN nanoparticles into magnesium EK21 matrices by electromagnetic stirring have been assessed. The following conclusions can be drawn: the creep threshold of the samples containing nanoparticles is found to increase with respect to the unreinforced alloy, and the flow stress rises up by 20 to $50 \%$, which supports other studies found in literature but here for higher temperature ranges. Threshold stresses up to $50 \mathrm{MPa}$ are obtained with the composites. This value decreases as creep temperature increases and an activation energy of $163 \mathrm{~kJ} / \mathrm{mol}$ is obtained in the range $350-450^{\circ} \mathrm{C}$. The particles also showed a high reactivity with magnesium producing different compounds with the rare earths element present in the alloy, which could have also contributed to the reinforcement of the alloy and the threshold stresses. The reaction kinetics are found faster likely because of the strong electromagnetic stirring. In spite of a similar lattice parameter, AlN particles did not produce any grain refinement at the casting conditions in which the samples were produced. This could be related to the reaction of the particles with the zirconium present in the alloy forming stable particles that poisons the grain refining effect as well as some residual agglomeration of the particles.

\section{Data Availability Statement}

Some of the raw data required to reproduce these findings are available to download from the following web site, https://tel.archives-ouvertes.fr/tel-01688866/document.

All the processed data required to reproduce these findings are available to download from the following web site, https://tel.archives-ouvertes.fr/tel-01688866/document, where the $\mathrm{PhD}$ dissertation of Dr. Mariano Garrido is made available.

A remaining part of the raw data required to reproduce some findings cannot be shared at this time as these data also forms part of an ongoing study.

Acknowledgements. The authors wish to acknowledge financial support from the Exomet project, which is co-funded by the European Commission in the 7th Framework Programme (contract FP7-NMP3-LA-2012-280421) and by the European Space Agency. The authors are grateful to Dr. B. Rattoni from the Commissariat à l'Énergie Atomique (CEA) at Saclay. The laboratory SIMaP is part of the LabEx Tec 21 (Investissements d'Avenir, Grant Agreement ANR-11-LABX-0030).

\section{Annex 1}

A picture of the AlN clusters which could be detected is shown in Figure 11a. Using the software imageJ plugin 3D object counter (cf. Ref. [25]) the position in the space of the centroid of each agglomerate is measured and displayed in the isometric view (Fig. 11b). A Matlab code based on Delaunay triangulation has been developed to calculate the average interparticle (agglomerate) distance using the position of the centroid of each particle. The sample presents particles (agglomerates) dispersed within a single $\alpha$ magnesium grain. In this case, the average interparticle distance calculated is $30.29 \mu \mathrm{m}$, and the average volume around one particle cluster $178 \mu \mathrm{m}^{3}$. Considering the shape of the particle clusters to be fairly approximated as spheres, the average size of a cluster, as calculated, is $5.83 \mu \mathrm{m}$.

\section{Annex 2}

Batchelor [26] analyzed mass transfer around small rigid spherical particles suspended in fluid. The fluid is in 


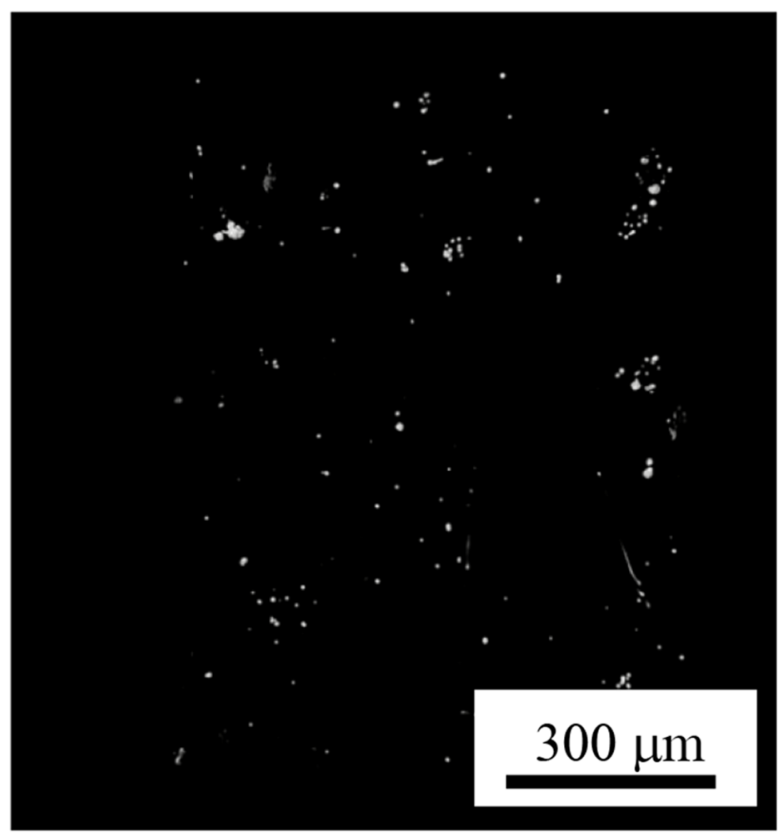

(a)

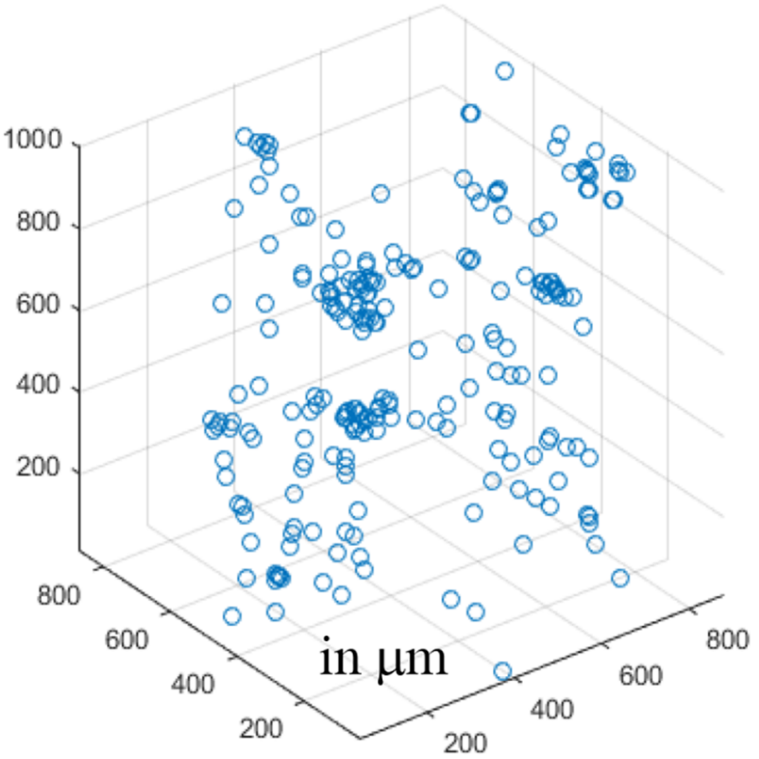

(b)

Fig. 11. a: View of aluminium nitride clusters detected by tomography in magnesium EK21 $+1 \%$ AlN particles; b: Isometric plot of particles; c: distribution of the AlN particle cluster sizes.

statistically steady turbulent motion. The flow around a particle is a superposition of (a) a streaming flow due to a translational motion of the particle relative to the fluid with a velocity proportional to the density difference, and (b) a flow due to the velocity gradient in the ambient fluid. For small particles, the translational motion is weak, and the latter mechanism is dominant. Batchelor provided an expression of the final non-dimensional expression for the transfer rate (or Sherwood number) in terms of the mean turbulent dissipation rate $\varepsilon$ (in $\mathrm{W} / \mathrm{kg}$ ), which is obtained from the computation of the turbulent fluid flow by means of the $k$-e model. The expression of the Sherwood number $S h$ is:

$$
S h=2+0.35\left[d^{2} \varepsilon^{1 / 2} /\left(D_{m} v^{1 / 2}\right)\right]^{1 / 3},
$$

where $d, D m$ and $n$ respectively denote the particle diameter, the molecular chemical diffusion coefficient and the kinematic viscosity. In Relation (A1), the second term in the RHS account for the effects of liquid metal turbulence on mass transfer around a particle, whereas the effect of pure molecular diffusion corresponds to $S h=2$. Taking $\varepsilon \approx 10^{-2} \mathrm{~m}^{2} \mathrm{~s}^{-3}$ (computed average value), $D_{m} \approx 10$ ${ }_{-9} \mathrm{~m}^{2} \mathrm{~s}^{-1}$, and $v \approx 0.75 \times 10^{-6} \mathrm{~m}^{2} \mathrm{~s}^{-1}$ the numerical values of the Sherwood number are:

$-S h=2.02$ for $d=30 \mathrm{~nm}$;

$-S h=2.56$ for $d=5.8 \mu \mathrm{m}$.

The latter estimates indicate that the influence of convection on mass transfer is significant only for particle clusters significantly larger than $5.8 \mu \mathrm{m}$. Mass transfers are essentially driven by chemical diffusion, and the main interest of electromagnetic stirring is to cause a better dispersion of particles.

\section{References}

1. W. Chen, M.C. Chaturvedi, Acta Mater. 45, 2735-2746 (1997)

2. T.H. Courtney, Mechanical behavior of materials, 2nd ed., Waveland Pr Inc., 2005

3. H. Ferkel, B.L. Mordike, Mater. Sci. Eng. A 298, 193-199 (2001)

4. Y.Q. Liu, H.T. Cong, W. Wang, C.H. Sun, H.M. Cheng, Mater. Sci. Eng. A 505(1-2), 151-156 (2009)

5. M. Paramsothy, J. Chan, R. Kwok, M. Gupta, J. Nanotechnology 2012, 8 (2012) Article ID 687306, DOI: $10.1155 / 2012 / 687306$

6. J. Chen, B. Chong-Gao, Acta Metall. Sin. 28(11), 1354-1363 (2015)

7. I.M. Rajat Banerjee, Ceramic nanocomposites, 1st ed., Woodhead Publishing, 2013

8. D. Zhang, K. Sugio, K. Sakai, H. Fukushima, O. Yanagisawa, Mater. Trans. 48(2), 171-177 (2007)

9. V. Bojarevics, K. Pericleous, M. Garrido, Y. Fautrelle, L. Davoust, Magnetohydrodynamics 51(3), 453-459 (2015)

10. W. Qiu, E. Han, L. Liu, Mater. Sci. Technol. 25(4), 441-444 (2009)

11. D. Findley, J. Lai, K. Onaran, J. Appl. Math. Mech. 58(11), 477-528 (1978)

12. H. Somekawa, K. Hirai, H. Watanabe, Y. Takigawa, K. Higashi, Mater. Sci. Eng. A 407(1-2), 53-61 (2005) 
13. W. Horn-Yu, Y. Jie-Chen, Mater. Sci. Mech. Eng. 535, 68-75 (2012)

14. L. Katsarou, M. Mounib, W. Lefevre, S. Vorozhtsov, M. Pavese, C. Badini, J. Molina-Cepeda, M.T. Perez Pradoe, H. Dieringa, Mater. Sci. Eng. 659, 84-9 (2016)

15. L.-C. Yang, Y.-T. Pan, I.-G. Chen, D.-Y. Lin, Metals (Basel) 5(3), 1717-1731 (2015)

16. H. Frost, M. Ashby, Deformation-mechanism maps, 1st ed., Pergamon Press, 1982

17. M. Barnett, A. Atwell, G. Beer, Mater. Sci. Forum 467-470, 435-440 (2004)

18. G. Klosch, B. McKay, P. Schumacher, Essential readings in magnesium technology, John Wiley \& Sons, Ed. 2014

19. J. Wang, J. Yang, W. Yaoming, Z. Hongjie, L. Wang, Mater. Sci. Eng. A 472(1-2), 332-337 (2008)
20. L. Wei, G. Dunlop, H. Westengen, Mater. Sci. Technol. 12 (9), 741-750 (2013)

21. M. Avedesian, B. Hugh, ASM specialty handbook: Magnesium and magnesium alloys, 1999

22. K. Meschinchi Asl, Magnesium alloy, in: F. Czerwinski (Ed.), Des. Process. Prop., ISBN: 978-953-307-520-4, In Tech, pp. 265-280, 2011

23. A. Saboori, E. Padovano, M. Pavese, C. Badini, Materials 11 (1), 2017, DOI: 10.3390/ma11010027

24. M. Mounib, M. Pavese, C. Badini, W. Lefebvre, H. Dieringa, Adv. Mater. Sci. Eng. 2014, 6 (2014), Article ID 476079, DOI: $10.1155 / 2014 / 476079$

25. S. Bolte, F.P. Cordelières, J. Microsc. 224(3), 213-232 (2006)

26. G.K. Batchelor, J. Fluid Mech. 98(3), 609-623 (1980)

Cite this article as: Mariano Garrido, Laurent Davoust, Rémi Daudin, Luc Salvo, Wim Sillekens, Yves Fautrelle, Reinforcement of magnesium Elektron 21 with aluminium nitride (AlN) nanoparticles dispersed using a travelling magnetic field, Metall. Res. Technol. 107, $203(2020)$ 